\title{
Exame Histopatológico em Espécimes de Doença Hemorroidária Operada - Revisão de 2.134 Casos
}

\author{
Histopathologic Examination of Hemorrhoids: Review of 2.134 cases of \\ Hemorrhoidectomy
}

\author{
GERALDO MAGELA GOMES DA CRUZ'; JORGE LUIZ SANTANA ${ }^{2}$; SANDRA KELY ALVES DE ALMEIDASANTANA ${ }^{2}$; \\ JOSÉ ROBERTO MONTEIRO CONSTANTINO²; BRUNO CUNHACHAMONE ${ }^{2}$; RENATAMAGALI RIBEIRO SILLUZIO \\ FERREIRA $^{3}$; PETERSON MARTINS NEVES $^{3}$; MARINANEVES ZERBINI DE FARIA $^{4}$ \\ ${ }^{1}$ Mestre, Doutor e Professor Titular de Coloproctologia, TSBCP, TFBG, TALACP, TCBC, TISUCRS, FASCRS; ${ }^{2}$ Pós- \\ graduandos lato sensu em Coloproctologia; ${ }^{3}$ Assistentes do Grupo de Coloproctologia; ${ }^{4}$ Estagiária Voluntária do \\ Serviço de Coloproctologia.
}

CRUZ GMG; SANTANA JL; SANTANA SKAA; CONSTANTINO JRM; CHAMONE BC; FERREIRA RMRS; NEVES PM; FARIA MNZ. Exame Histopatológico em Espécimes de Doença Hemorroidária Operada - Revisão de 2.134 Casos. Rev bras Coloproct, 2007;27(3): 269-277.

RESUMO: Em 34.000 pacientes coloproctológicos atendidos em 38 anos, foi feito o diagnóstico de DH como doença principal em 9.289 pacientes $(\mathbf{2 7 , 3 \%})$, dos quais $2.417(\mathbf{2 6 , 0} \%)$ foram submetidos à hemorroidectomia, tendo sido feito exame histopatológico em peças cirúrgicas de 2.134 pacientes $(\mathbf{8 8 , 3 \%})$. O objetivo deste trabalho é analisar os resultados dos exames histopatológicos dos 2.134 espécimes examinados e confronta-los com a literatura correlata. O EHP corroborou 100\% dos diagnósticos de DH nos 2.134 espécimes examinados. $O$ exame proctológico constatou doenças anais concomitantes (DAC) à DH em 1.122 pacientes dos 9.289 pacientes portadores de DH (12,1\%); dos 2.417 pacientes operados de DH, a cirurgia foi em conjunto com as DAC em 729 pacientes (30,2\%); e o EHP confirmou as DAC em 530 dos 729 espécimes examinados (72,8\%). Os diagnósticos de DAC operadas que atingiram os mais elevados índices de confirmação pelo EHP foram: 100,0\% dos 89 casos de fístula anal, 100,0\% dos 22 casos de condilomas anais acuminados, 79,0\% (211) dos 267 casos de hipertrofia de papilas anais, 68,5\% (217) dos 317 casos de fissura anal e $66,7 \%$ ( 2 casos) dos 3 casos de tumor anal. O EHP detectou, nos 2.134 espécimes, 37 casos de outras doenças não diagnosticadas antes da cirurgia (1,7\%), que foram, por ordem de freqüência: esquistossomose (18 casos), amebíase (5 casos), doença de Crohn anal ( 4 casos), melanoma anal ( 2 casos), CCE ( 2 casos), doença de Bowen ( 2 casos), tuberculose anal ( 2 casos), câncer cloacogênico (1 caso) e linfoma (1 caso). Os autores concluem que é extremamente importante a realização do EHP em todos os espécimes cirúrgicos de hemorroidectomia, tanto para corroborar o diagnóstico de DH, quanto para corroborar diagnósticos pré-operatórios de doenças anais concomitantes à $\mathrm{DH}$, e mesmo doenças anais concomitantes não detectáveis pelo exame proctológico.

Descritores: Doença hemorroidária; exame histopatológico; hemorroidectomia; exame histopatológico de hemorróidas.

\section{INTRODUÇÃO}

Várias bactérias, parasitas, fungos e vírus são capazes de produzir doenças na região anorretal. Há inúmeros procedimentos de Patologia Clínica para a confirmação ou não do diagnóstico das doenças infectocontagiosas e parasitárias. Hoje, além dos tradicionais exames, há grandes avanços no setor da imunologia.
Já fazem parte do arsenal de diagnóstico de rotina técnica de radioimunoensaio, imunofluorescência e ELISA. Sondas de DNA e RNA estão chegando aos laboratórios comerciais ligados à universidade, tudo isso contribuindo para um exame complementar mais seguro. Hoje as infecções viróticas, bacterianas, fúngicas e parasitárias são melhor diagnosticadas, e o acompanhamento terapêutico das mesmas é, sem dúvida, bem mais

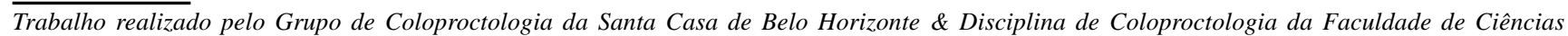
Médicas de Minas Gerais. 
simples. Estas técnicas estão sendo também empregadas na Anatomia Patológica (estudo de tumores, etc.) e na genética, o que contribuiu em muito para o avanço da Ciência Médica 1, 2, 14, 16, 20, 21, 23, 25, 26, 28, 29, 33.

Exame histopatológico (histo=tecido, pathos= doença e logus= estudo) é o estudo das doenças do ponto de vista morfológico (macro e microscópico). Tem aplicação corrente na medicina para diagnóstico das doenças através de suas alterações histológicas. O produto final deste é o laudo anatomopatológico, que representa o resultado do exame e contém o diagnóstico da doença, e dependendo do caso, a extensão e as complicações da mesma, bem como quadros associados ${ }^{1}$, 2, 26, 28, 29, 33 .

É necessário também evitar pinçamentos, esmagamentos, trações e outros manuseios que possam alterar a morfologia do tecido. O material colhido deve ser colocado imediatamente em solução fixadora. A fixação é imprescindível porque impede a autólise do tecido, enrijece o material mantendo as células e o estroma em condições próximas de seus aspectos no vivo, permitindo assim o estudo morfológico. Para estudo histológico de rotina, usa-se solução aquosa de formol a $10 \%$, que satisfaz plenamente e é de baixo custo. Em casos especiais o cirurgião deve discutir com o patologista sobre qual fixador utilizar. O volume de fixador indicado é de no mínimo três vezes o volume do material a ser fixado. A peça cirúrgica deve ser encaminhada ao laboratório em frasco rotulado e com a requisição do exame, contendo os dados de identificação do paciente (nome completo e legível, idade, profissão e sexo), natureza e sede do material enviado para exame e dados clínicos (a orientação clínica é fundamental para diagnóstico correto) 1, 2, 26, 28, 29, 33 .

O canal anal, em sua porção superior é revestido por mucosa semelhante à do intestino grosso. A porção inferior do canal anal é revestida por um epitélio pavimentoso estratificado. Entre as duas porções há uma quantidade variável de epitélio cilíndrico ou cúbico estratificado, que é chamado de epitélio transicional, intermediário ou cloacogênico. O epitélio pavimentoso estratificado da porção inferior do canal anal é contínuo com o da pele, onde se torna ceratinizado. Na pele da região perianal, localizam-se glândulas apócrinas, chamadas glândulas perianais. $\mathrm{O}$ canal anal é circundado por um grupo de músculos formando esfíncteres. $\mathrm{O}$ interno é formado por um espessamento da camada muscular circular. O esfíncter externo é constituído por músculo estriado. Na lâmina própria há um grande nú- mero de linfócitos, difusamente distribuídos ou aglomerados em nódulos linfáticos. Alterações vasculares: a mais freqüente é a doença hemorroidária caracterizada por dilatação varicosa dos plexos venosos hemorroidários. Hemorróidas internas são derivadas das veias hemorroidárias superiores, e as externas das veias hemorroidárias inferiores, e são revestidas por mucosa escamosa. $\mathrm{O}$ exame microscópico revela vasos submucosos dilatados, podendo haver trombose ou ulceração do epitélio de revestimento 1, 2, 26, 28, 29, 33 .

O exame histológico é muito importante, devido à possibilidade de se descobrir uma neoplasia maligna em lesões clinicamente diagnosticadas como simples processos hemorroidários 1, 2, 4, 7, 10, 11, 13, 22, 26, 27, 28, 29, 32, 33, destacando-se entre eles o carcinoma de células escamosas do ânus e do canal anal 4, 11, 13, 22, 27, 32. Outros tumores, não tão freqüentes podem ocorrer, como os carcinomas muco-epidermóides 4 , 11, 13, 22, 27 , os carcinomas adenóide-císticos 11, 13, 27, os sarcomas 4,11, 13, 27 e a doença de Paget 11, 13, 27. Outros tumores, como os melanomas, podem mimetizar, para os menos avisados, uma trombose hemorroidária 4, 7, 10, 11, 13, 22, 27, 30. Outras doenças associadas podem ocorrer, como parasitoses ${ }^{8,20,21,31}$ (sobretudo esquistossomose ${ }^{31}$ ), micoses profundas 14, 20,21,23, 25 (sobretudo actino e blastomicose ${ }^{16,21}$ ), infecção pelo HPV (Human Papiloma Virus) 3, 5, 6, 20,21, processos inflamatórios inespecíficos ${ }^{21,24,27}$ e específicos 19,21, 27 (sobretudo tuberculose ${ }^{19}$ ), doenças sexualmente transmissíveis 9 , 20, 21, 34, papilites e criptites anais 12,17, 21, abscessos e fístulas de margem do ânus 15, 18, 21, 27, e fissuras anais sobretudo posteriores.

\section{OBJETIVO}

O objetivo deste trabalho é estudar os resultados de exames histopatológicos de 2.134 espécimes cirúrgicos de hemorroidectomia, analisando os diagnósticos de $\mathrm{DH}$ e de doenças anais concomitantes à DH (DAC), além de diagnósticos de outras doenças anais concomitantes não detectáveis ao exame proctológico; e traçar um paralelo com achados de relatos congêneres da literatura.

\section{CASUÍSTICA - PACIENTES E MÉTODO}

Em 34.000 pacientes coloproctológicos foi feito o diagnóstico de DH como doença coloproctológica principal em 9.289 pacientes $(27,3 \%)$, dos quais 2.417 
$(26,0 \%)$ foram submetidos à hemorroidectomia, tendo sido feito exame histopatológico em peças cirúrgicas de 2.134 pacientes $(88,3 \%)$. O material de estudo consiste dos 2.134 espécimes cirúrgicos provenientes da cirurgia para DH, como doença de base, em 2.417 pacientes.

\section{RESULTADOS}

Incidência de exame histopatológico de 2.134 peças de 2.417 pacientes submetidos à hemorroidectomia: a tabela 1 mostra que de 34.000 pacientes coloproctológicos, 9.289 (27,3\%) eram portadores de doença hemorroidária (DH), dos quais 2.417 vieram a ser operados desta doença $(26,0 \%)$, e que dos espécimes ressecados, 2.134 (88,3\%) foram enviados para exame histopatológico, ficando 283 espécimes cirúrgicos $(11,7 \%)$ sem este exame. Os mesmos dados são mostrados pela figura 1, em que aparecem colunas representativas de todos os eventos descritos.

Incidência das várias doenças anais concomitantes (1.122 casos) em pacientes portadores de DH (9.289 casos), ao exame proctológico: dos 9.289 pacientes que receberam diagnóstico de DH ao exame proctológico, $1.122(12,1 \%)$ receberam, também, diagnósticos de doenças anais concomitantes à DH. Entre as DAC figuram a fissura anal e 541 pacientes $(5,8 \%)$, a hipertrofia de papilas anais ou papilite em $312(3,4 \%)$ pacientes, fístulas anais em 117 pacientes $(3,4 \%)$, hipotonia esfincteriana com incontinência anal parcial em 112 pacientes $(1,2 \%)$, condilomas anais acuminados em 37 pacientes $(0,4 \%)$ e tumores anais em 3 pacientes $(0,03 \%)$ (tabela 2, colunas A e B e figuras 2, 3, 4 e 5).

Tabela 1 - Exames histopatológicos (EHP) em 2.134 peças cirúrgicas oriundas de 2.417 pacientes submetidos à hemorroidectomia, por sua vez provenientes de 9.289 pacientes portadores de DH, extraídos de um universo de 34.000 exames proctológicos.

\begin{tabular}{lrr}
\hline EHP & $\mathbf{N}$ & \multicolumn{1}{c}{$\%$} \\
\hline N de pacientes atendidos & 34.000 & \\
N de portadores de DH & 9.289 & $27,3 \%$ \\
N de portadores de DH operados & 2.417 & $26,0 \%$ \\
Pacientes operados & 2.417 & $100,0 \%$ \\
EHP realizados & 2.134 & $88,3 \%$ \\
EHP não realizados & 283 & $11,7 \%$ \\
\hline
\end{tabular}

Incidência das várias doenças anais concomitantes em relação ao total de 1.122 casos, diagnosticados ao exame proctológico: as incidências entre as várias DAC à DH foram: fissura anal $48,2 \%$, hipertrofia de papilas anais ou papilites $27,8 \%$, fístulas anais $10,4 \%$, hipotonia esfincteriana com incontinência anal parcial 10,0\%, condilomas anais acuminados $3,3 \%$ e tumores perianais $0,03 \%$ (tabela 2, coluna $\mathrm{C}$ e figuras $2,3,4$ e 5).

Incidência das várias DAC, do total de 729 operadas simultaneamente aos 2.417 pacientes operados de DH: dos 2.417 pacientes operados de DH, 729 (30,1\%) foram operados, em concomitância, de DAC, assim distribuídas: 317 casos de fissuras anais (13,1\%), 267 casos de hipertrofia de papilas anais ou papilites (11,0\%), 89 casos de fístulas anais $(13,7 \%)$, 31 casos de hipotonia com incontinência anal parcial (1,3\%), 22 casos de condilomas anais acuminados $(0,9 \%)$ e 3 casos de tumores anais $(0,1 \%)$ (tabela 2, colunas "D" e figuras $2,3,4$ e 5 ).

Proporção cada Doença anal concomitante diagnosticada e operada em concomitância com a hemorroidectomia: foram operados 317 dos 541 portadores de fissura anal $(58,6 \%), 267$ dos 312 portadores de hipertrofia de papilas anais ou papilites $(85,6 \%)$, 89 dos 117 portadores de fístulas anais $(76,0 \%), 31$ dos 112 portadores de hipotonia esfincteriana com incontinência anal parcial $(25,8 \%), 22$ dos 37 portadores de

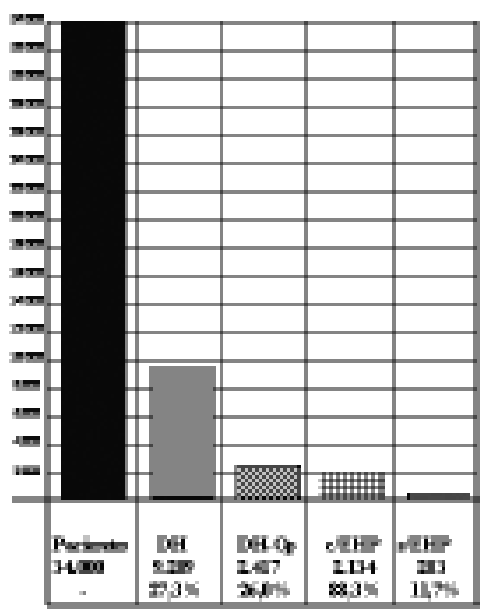

Figura 1 - Colunas representativas de 34.000 pacientes proctológicos, dos quais 9.289 eram portadores de doença hemorroidária (DH), dos quais 2.417 foram submetidos à hemorroidectomia (DH-Op), tendo sido 2.134 espécimes cirúrgicas submetidos a exame histopatológico (c/EHP), ficando $283 \mathrm{sem}$ o referido exame ( $s / E H P)$. 
condilomas anais acuminados $(59,5 \%)$ e os 3 pacientes que receberam diagnóstico de tumores anais concomitantes à DH $(100,0)$ (tabela 2 coluna $\mathbf{F}$ e figuras 2, 3, 4 e 5).

Exame histopatológico de 2.134 peças cirúrgicas, traçando um paralelo entre os resultados e os diagnósticos de Doenças anais concomitantes feitos ao exame proctológico: em relação às DAC a tabela 3 mostra que o EHP corroborou o diagnóstico clínico-proctológico de 217 dos 317 casos de fissura anal $(68,5 \%), 211$ dos 267 casos de hipertrofia de papilas anais $(79,0 \%)$, todos os 89 casos de fístulas anais $(100,0 \%)$, todos os casos de condilomas anais $(100,0 \%)$ e 2 dos 3 casos de tumor anal $(66,7 \%)$, ten-

Tabela 2 - Incidência de doenças anais concomitantes (DAC) à DH em 9.289 pacientes portadores de DH ao exame proctológico, em números absolutos (coluna A); incidência das 729 casos de DAC operadas simultaneamente aos 2.417 pacientes operados de DH, em números absolutos (coluna B) e em números percentuais indicando a proporção entre cada DAC diagnosticada e operada em concomitância com a cirurgia para a DH (coluna $C$ ).

\begin{tabular}{lccc}
\hline \multirow{2}{*}{$\begin{array}{l}\text { Doenças anais } \\
\text { concomitantes à DH }\end{array}$} & $\mathbf{A}$ & $\mathbf{B}$ & $\mathbf{C}$ \\
\cline { 2 - 4 } & $\begin{array}{c}\text { N-DAC relativo } \\
\mathbf{9} \mathbf{9 . 2 8 9}\end{array}$ & N-DAC operados & $\begin{array}{c}\text { \%-DAC : \% - } \\
\text { DAC operados }\end{array}$ \\
\hline Fissura anal & 541 & 317 & $58,6 \%$ \\
Hipertrofia de papilas anais & 312 & 267 & $85,6 \%$ \\
Fístula anal & 117 & 89 & $76,0 \%$ \\
Hipotonia com incont. parcial & 112 & 31 & $25,8 \%$ \\
Condilomas anais acuminados & 37 & 22 & $59,5 \%$ \\
Tumor perianal & 3 & 3 & $100,0 \%$ \\
Total & 1.122 & 729 & \\
\hline
\end{tabular}

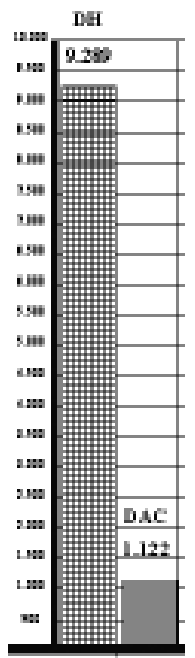

Figura 2 - Incidência global de 1.122 casos de doenças anais concomitantes (DAC) diagnosticadas ao exame proctológico, englobando fissura anal posterior (FAP), hipertrofia de papila anal (HPA), fístula perianal (FtPA), hipotonia esfincteriana (Hpo), condilomas anais acuminados (CAA) e tumor perianal (TPA), em relação aos 9.289 pacientes portadores de $\mathrm{DH}$.

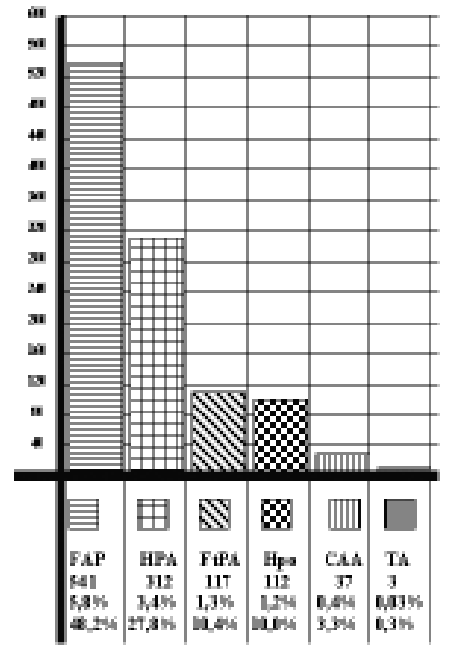

Figura 3 - Incidências de doenças anais concomitantes (DAC) diagnosticadas ao exame proctológico (1.122 casos) - fissura anal posterior (FAP), hipertrofia de papila anal (HPA), fístula perianal (FtPA), hipotonia esfincteriana (Hpo), condiloma anal acuminado (CAA) e tumor perianal (TPA) - em relação aos pacientes portadores de DH (9.289 casos) em números absolutos e percentuais e em relação às próprias $D A C$. 


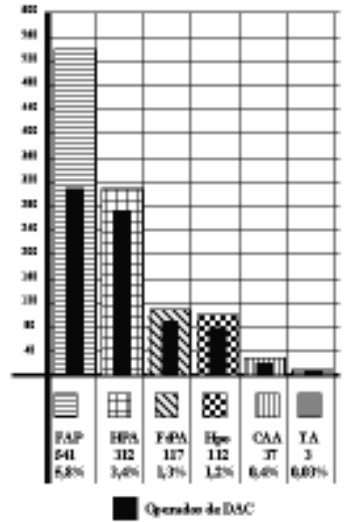

Figura 4 - Incidências de doenças anais concomitantes (DAC) diagnosticados ao exame proctológico (1.122 casos) - fissura anal posterior (FAP), hipertrofia de papila anal (HPA), fístula perianal (FtPA), hipotonia esfincteriana (Hpo), condiloma anal acuminado (CAA) e tumor perianal (TPA) - em relação aos 9.289 pacientes portadores de doença hemorroidária $(\mathrm{DH})$, em números absolutos e em percentuais e em relação entre elas (DAC), nas colunas com fundos marcados; e incidência de DAC operadas ( 729 casos) realizadas concomitantemente à cirurgia para DH (2.417 casos), em números absolutos e em percentuais (colunas em negrito).

do sido, por motivos óbvios (não há geração de espécimes cirúrgicos), descartados os diagnósticos clínico-proctológicos de hipotonia esfincteriana com incontinência anal parcial. Assim, o EHP corroborou 541 diagnósticos de DAC dos 729 pacientes operados de DAC (tabela 3 e figura 6) associado à DH $(72,8 \%)$.

Diagnósticos pelo EHP de Doenças anais concomintantes à DH não realizados pelo exame proctológico: o EHP detectou, em 37 dos 2.134 espécimes cirúrgicos, doenças não diagnosticadas no pré-operatório $(1,7 \%)$ (tabela 4 e figuras 6 e 7): esquistossomose (18 casos), amebíase (5 casos), doença de Crohn anal (4 casos), melanoma anal (2 casos), CCE ( 2 casos), doença de Bowen ( 2 casos), tuberculose anal ( 2 casos), câncer cloacogênico (1 caso) e linfoma (1 caso).

\section{DISCUSSÃO}

Foi impossível aferir nossos dados com a literatura, por falta absoluta de publicações sobre o assunto em pauta, talvez relegado a um segundo ou terceiro plano em decorrência da simplicidade da própria matéria, e não pela sua importância. Não encontramos publicações sobre este assunto nos últimos 10 anos na Revista Brasileira de Coloproctologia e na Diseases of Colon and Rectum.

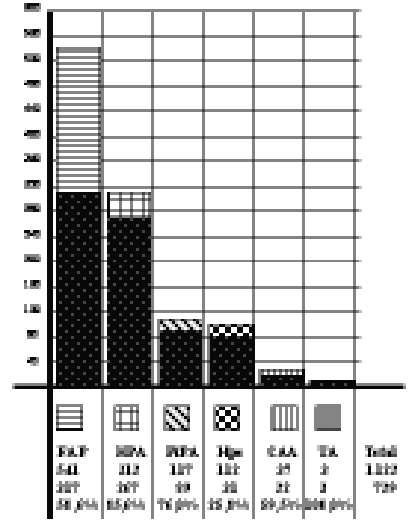

Figura 5 - Incidência de cirurgias em doenças anais concomitantes (DAC) ( 729 casos) realizadas concomitantemente à cirurgia para doença hemorroidária $(\mathrm{DH})$ (2.417 casos), em relação aos casos de DAC diagnosticadas (1.122 casos) englobando fissura anal posterior (FAP), hipertrofia de papila anal (HPA), fístula perianal (FtPA), hipotonia esfincteriana (Hpo), condiloma anal acuminado (CAA) e tumor perianal (TPA).

Encontramos o resumo de um tema livre apresentado no $48^{\circ}$ Congresso Brasileiro de Coloproctologia (Tema Livre 59) - Carneiro LLR et al. ${ }^{4}$ "Exame histopatológico de peças cirúrgicas de hemorroidectomia" (Revista Brasileira de Coloproctologia, 19 - Suplemento 1, página 43, 1999), não publicado sob forma de artigo, em que os autores analisam o diagnóstico histopatológico de produtos de hemorroidectomia em 145 pacientes consecutivos, no período de janeiro a dezembro de 1998. Entre os diagnósticos de doenças associadas observaram-se: 6 casos $(4,1 \%)$ de esquistossomose, 4 casos $(2,8 \%)$ de lesões por HPV, 2 casos $(1,4 \%)$ de proctite crônica inespecífica e 1 caso $(0,7 \%)$ de nevo intradérmico. Não houve casos de malignidade associada. Não foram relatados diagnósticos de doenças anais concomitantes diagnosticadas previamente por ocasião do exame proctológico (e.g., fístulas, fissuras, papilites anais, dentre outras). Os autores ${ }^{4}$ concluem que há relevância no exame histopatológico das peças cirúrgicas de hemorroidectomia devido à ocorrência de outras doenças anais associadas, aconselhando exame histopatológico de todo material proveniente de hemorroidectomias.

De 2417 pacientes operados, 2.134 peças cirúrgicas foram encaminhadas para exame histopatológico $(88,3 \%)$, tendo 283 espécimes cirúrgi$\cos (11,7 \%)$ ficado sem este exame. Os casos de espécimes não encaminhados para exame foram os primeiros operados, quando ainda não era hábito, em nosso meio, o exame de todos os espécimes cirúrgicos, 
Tabela 3 - Exame histopatológico (EHP) de 2.134 peças cirúrgicas, traçando um paralelo entre: (a) resultados deste exame com o diagnóstico clínico-proctológico das várias DAC (coluna A), (b) das DAC operadas (coluna B), (c) dos diagnósticos histopatológicos das DAC operadas (coluna C) e (d) do percentual dos diagnósticos pelo EHP e pelo exame clínico-proctológico (coluna D).

\begin{tabular}{lcccc}
\hline & $\mathbf{A}$ & $\mathbf{B}$ & $\mathbf{C}$ & $\mathbf{D}$ \\
\cline { 2 - 5 } $\begin{array}{l}\text { DAC operadas em } \\
\text { concomitância à DH }\end{array}$ & $\begin{array}{c}\text { DAC+DH } \\
\mathbf{9 . 2 8 9}\end{array}$ & $\begin{array}{c}\text { N operados } \\
\text { DAC+DAC }\end{array}$ & $\begin{array}{c}\text { N diagn HP com } \\
\text { diagn. clinico }\end{array}$ & $\begin{array}{c}\text { \% diagn HP e } \\
\text { diagn clínico }\end{array}$ \\
\hline Fissura anal & 541 & 317 & 217 & $68,5 \%$ \\
Hipertrofia de papila anal & 312 & 267 & 211 & $79,0 \%$ \\
Fístula anal & 117 & 89 & 89 & $100,0 \%$ \\
Hipotonia esfincteriana & 112 & 31 & - & - \\
Condiloma anal acuminado & 37 & 22 & 22 & $100,0 \%$ \\
Tumor anal & 3 & 3 & 2 & $66,7 \%$ \\
Total & 1.122 & 729 & $541-31=510$ & $72,8 \%$ \\
\hline
\end{tabular}

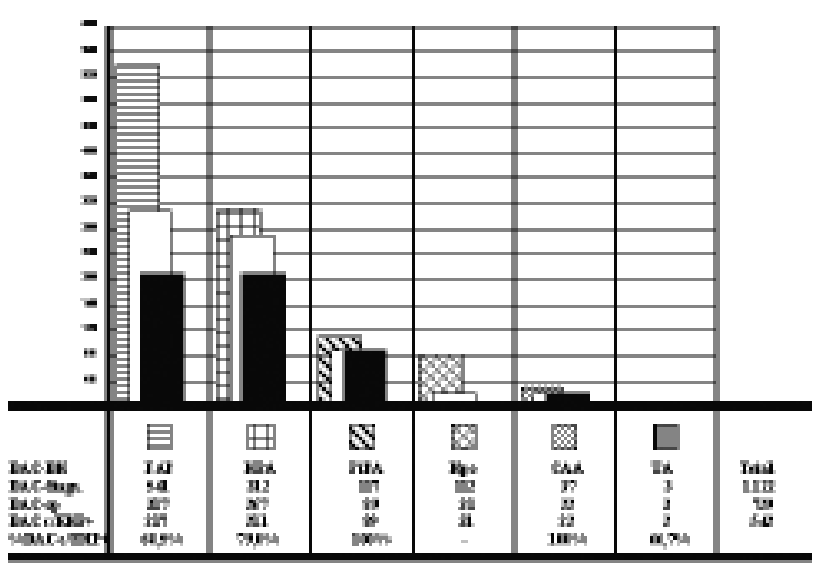

Figura 6 - Incidência de doenças anais concomitantes à doença hemorroidária (DAC-DH) diagnosticadas (DAC-diagn) (colunas marcadas); incidência de DAC operadas e de peças enviadas para exame histopatológico (DAC-op) (colunas brancas); e incidência, em números absolutos e percentuais, de resultados positivos do EHP para a DAC de suspeita clínica (colunas em negrito) (DAC c/ $E H P+e \% D A C c / E H P+)$; englobando, respectivamente cada uma das DAC - fissura anal posterior (FAP), hipertrofia de papila anal (HPA), fístula perianal (FtPA), hipotonia esfincteriana (Hpo), condiloma anal acuminado (CAA) e tumor perianal (TPA).

sendo examinados apenas as peças que apresentavam suspeitas.

Por ocasião do exame proctológico, dos 9.289 pacientes que receberam diagnóstico de $\mathrm{DH}, 1.122$ $(12,1 \%)$ tinham, também, várias doenças anais concomitantes, sobretudo fissura anal (541 pacientes, $5,8 \%$ ), hipertrofia de papilas anais ou papilite (312 pacientes, 3,4\%), fístulas anais (117 pacientes, 3,4\%), hipotonia esfincteriana com incontinência anal parcial (112 pacientes, $1,2 \%$ ), condilomas anais acuminados (37 pacientes, $0,4 \%$ ) e tumores anais (3 pacientes, $0,03 \%)$

Dos 2.417 pacientes operados de DH, 729 (30,1\%) foram operados, em concomitância, de DAC, assim distribuídas: 317 casos de fissuras anais $(13,1 \%)$, 267 casos de hipertrofia de papilas anais ou papilites $(11,0 \%), 89$ casos de fístulas anais $(13,7 \%), 31$ casos de hipotonia com incontinência anal parcial $(1,3 \%), 22$ casos de condilomas anais acuminados $(0,9 \%)$ e 3 casos de tumores anais $(0,1 \%)$.

O EHP, além de diagnosticar a doença hemorroidária, corroborou o diagnóstico clínicoproctológico de 217 dos 317 casos de fissura anal (68,5\%), 211 dos 267 casos de hipertrofia de papilas anais $(79,0 \%)$, todos os 89 casos de fístulas anais $(100,0 \%)$, todos os casos de condilomas anais $(100,0 \%)$ e 2 dos 3 casos de tumor anal $(66,7 \%)$, tendo sido, por motivos óbvios (não há geração de espécimes cirúrgicos), descartados os diagnósticos clínico-proctológicos de hipotonia esfincteriana com incontinência anal parcial. Destarte EHP corroborou 541 diagnósticos de DAC dos 729 pacientes operados de DAC associado à DH $(72,8 \%)$. E, mais, ainda, o EHP detectou, em 37 dos 2.134 espécimes cirúrgicos, doenças não diagnosticadas no pré-operatório $(1,7 \%)$, como esquistossomose (18 casos), amebíase (5 casos), doença de Crohn anal (4 casos), melanoma anal (2 casos), CCE (2 casos), doença de Bowen ( 2 casos), tuberculose anal (2 casos), câncer cloacogênico (1 caso) e linfoma (1 caso). 
Tabela 4 - Diagnósticos pelo exame histopatológico (EHP) de outras doenças anais concomitantes à doença hemorroidária $(\mathrm{DH})$ não realizados pelo exame proctológico.

\begin{tabular}{lc}
\hline $\begin{array}{l}\text { Diagnósticos pelo EHP (37 casos) não feitos pelo exame proctológico, } \\
\text { em 2.134 peças cirúrgicas }(\mathbf{1 , 7 \%})\end{array}$ & N \\
\hline Esquistossomose & 18 \\
Amebíase & 5 \\
Doença de Crohn anal & 4 \\
Melanoma & 2 \\
CCE & 2 \\
Bowen & 2 \\
Tuberculose anal & 2 \\
Câncer cloacogênico & 1 \\
Linfoma & 1 \\
Total & 37 \\
\hline
\end{tabular}

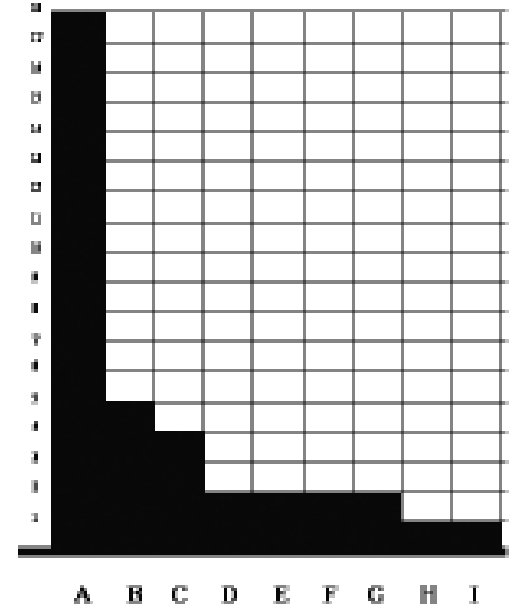

Figura 7 - Incidência de doenças anais concomitantes (DAC) à doença hemorroidária $(\mathrm{DH})$ diagnosticadas pelo exame histopatológico $(E H P)$ de 2.134 espécimes cirúrgicos de 2.417 pacientes submetidos à hemorroidectomia, e não realizados pelo exame proctológico antes da cirurgia: esquistossomose (A), amebíase histolítica $(B)$, doença de Crohn anal $(C)$, melanoma $(D), C C E(E)$, doença de Bowen $(F)$, tuberculose $(G)$, câncer cloacogênico $(H) e$ linfoma (I).

A série de Carneiro não aborda as DAC diagnosticadas por ocasião do exame proctológico (e.g., fissuras, fístulas, papilites). Aborda apenas os diagnósticos de DAC diagnosticadas ao EHP e refratárias ao diagnóstico pelo exame proctológico.

Comparando-se os 2.134 casos de EHP em DH da presente série com os 145 pacientes operados na série de Carneiro ${ }^{4}$, todos tendo as peças submeti- das ao EHP, constata-se que: a incidência de DAC à DH não diagnosticadas antes da cirurgia foi de 13 DAC para $145 \mathrm{DH}(9,0 \%)$, mas subtraindo-se os 4 casos de condilomas anais acuminados (para aferição com nosso material em que os 22 casos de condilomas foram diagnosticados antes da cirurgia) a incidência passa para 9 DAC para $145 \mathrm{DH}(6,2 \%)$; em nosso material a incidência foi de $37 \mathrm{DAC}$ para $2.134 \mathrm{DH}(1,7 \%)$, portanto muito acima da incidência daqueles autores ${ }^{4}$. A impressão que se tem não é a de que somente a grande diferença numérica de casos de DH (2.134 DH para $145 \mathrm{DH})$ explique tal diferença estatística $(6,2 \%$ para $1,7 \%)$. Na presente série ( 2.134 peças) foram encontrados 18 casos de esquistossomose $(0,8 \%)$ contra 6 casos em 145 espécimes $(4,1 \%)^{4}$. Tudo indica que esta diferença tão marcante estatisticamente seja devido ao habitat dos pacientes. Na presente série (2.134 peças) foram encontrados 4 casos de doença de Crohn $(0,2 \%)$ contra 2 casos em 145 espécimes $(1,4 \%)^{4}$. Na presente série (2.134 peças) foram encontrados 8 casos de tumores malignos $(0,4 \%)$ ( 2 casos de melanoma anal, 2 casos de CCE, 2 casos de doença de Bowen, 1 caso de câncer cloacogênico e 1 caso de linfoma), contra nenhum caso em 145 espécimes $(1,4 \%)^{4}$. Enquanto na presente série ( 2.134 peças) foram encontrados 4 casos de amebíase e 2 casos de tuberculose anal nenhum caso destas doenças foi encontrado na série de 145 espécimes $(1,4 \%)^{4}$. Em contrapartida, na série de 145 espécimes foi encontrado 1 caso de nevo intradérmico; na presente série, nenhum caso. Analisando-se a incidência de condilomas acuminados 
(HPV), a incidência foi muito maior na série de 145 casos ${ }^{4}$ (4 casos, 2,8\%) que na atual série (22 casos, $0,9 \%)$. Destarte, não houve concordância entre os achados da presente série (2.134 peças examinadas) e a série de 145 peças $^{4}$.

\section{CONCLUSÕES}

1. A incidência de hemorroidectomia foi de 26,0\% em portadores de $\mathrm{DH}$.

2. O EHP foi realizado em $88,3 \%$ dos 2.417 pacientes operados de $\mathrm{DH}$.

3. O EHP corroborou 100,0\% dos diagnósticos dos 2.134 pacientes operados de $\mathrm{DH}$.

4. O EHP corroborou $72,8 \%$ das 729 DAC operadas.
5. As incidências de diagnósticos de DAC operadas, pelo EHP foram: 100,0\% dos 89 casos de fístula anal, 100,0\% dos 22 casos de condilomas anais acuminados, 79,0\% (211) dos 267 casos de hipertrofia de papilas anais, 68,5\% (217) dos 317 casos de fissura anal e $66,7 \%$ ( 2 casos) dos 3 casos de tumor anal.

6. O EHP detectou 1,7\% (37 casos em 2.134 exames) de outras DAC não diagnosticados antes da cirurgia, sobretudo esquistossomose (18 casos).

7. É muito importante a realização do EHP de todos os espécimes cirúrgicos de hemorroidectomia, tanto para corroborar o diagnóstico de $\mathrm{DH}$, quanto para corroborar diagnósticos pré-operatórios de DAC e diagnosticar DAC não diagnosticadas no pré-operatório.

\begin{abstract}
The authors had the opportunity in a 38-year period of practice in Coloproctology, to attend 34,000 patients. Diagnose of hemorrhoids as the main cause of the symptoms was achieved in 9,289 patients (27.3\%) and 2,417 of them (26.0\%) underwent to haemohrroidectomy. Histopathologic examination was carried out in 2,134 specimens $(\mathbf{8 8 . 3 \%})$. The aim of this report is to analyse these patients as far as histopathologic examination is concerned as well as to compare our findings to other similar reports of the literature. The confirmation of hemohrroids was carried out in all of them (100.0\%). Associated anal diseases were found in 1,122 of 9,289 patients with the main diagnose of hamorrhoids (12.1\%). Among 2,417 patients who underwent haemohrroidectomy $729(30.2 \%)$ had surgery associated with anal diseases, and of these 729 cases, the histopathological examination reached the diagnosis in 530 specimens $\mathbf{( 7 2 . 8 \% )}$. Associated anal diseases with the highest proportion of confirmation of diagnose by the histopathologic examination were anal fistula (100.0\% of 89 operated patients), anal condyloma (100.0\% of 22 operated patients), hyperthrophied anal papilla (79.0\% or 211 of 267 operated patients), anal fissure (68.5\% or 217 of 317 operated patients) and anal cancer (66.7\% or 2 of 3 operated patients). The authors enphasise that histopathologic examination of surgical specimens of hemorrhoidectomy is very important, not only to confirm the main disease - hemorrhoids - but also to diagnose associated anal diseases found or not found preoperatively.
\end{abstract}

Key words: Hemorrhoids; Hemorrhoidectomy; examination; histopathological examination of piles.

\section{REFERÊNCIAS}

1. Andrade Filho, J.S. Biópsias do ponto de vista do patologista. In: Fonseca F.P., Savassi, PR. Cirurgia ambulatorial. 2a. ed., Editora Guanabara Koogan, 196-200, 1987.

2. Bogliolo L. Patologia. $5^{\text {a }}$ ed. Rio de Janeiro: Ed. Guanabara Koogan; 1994.

3. Brown DR, Bryan JT, Cramer H, Katz BP, Handy V, Fife $\mathrm{KH}$. Detection of multiple human Papillomavirus types in condylomata acuminata from immunosuppressed patients. J Infect Dis, 1994; 170(4):759-65.

4. Carneiro; LLR, Zerbini JC, Cruz GMG, Costa LMP, Silva IG, Miranda SML, Teixeira RG, Minarrini J, Lanna D, Júnior HNV, Lima MJR, Luz MMP, Pereira FSA, Silva GM, Khouri RM, Oliveira KA e Marques ET). Exame histopatológico de peças cirúrgicas de hemorroidectomia. Rev Bras de Coloproctologia, 19 - Suplemento 1, página 43, 1999).
5. Chu QD, Vezeridis MP, Libbey NP, Wanebo HJ. Giant Condyloma Acuminatum (Buschke-Löwenstein Tumor) of the Anorectal and Perianal Regions. Dis Colon Rectum, 1994;37:950-7.

6. Congilosi SM, Madoff RD. Current Therapy for recurrent and Extensive Anal Warts. Dis Colon Rectum, 1995;38:1101-7.

7. Coper, P.H., Mills S.E. Allen, M.S. Malignant melanoma of the anus: Report of 12 patients and analysis of 255 adicional cases. Dis. Colon Rectum, 25: 693, 1982.

8. Cruz GMG, Oliveira AT et Rodrigues JVL. Estudo retrospectivo de 870 exames proctológicos em pacientes de ária metropolitana. Rev Bras de Coloproctologia, 16 (4), 200-205, 1996.

9. Cruz GMA, Oliveira AT, Rodrigues JVL. Manifestações coloproctológicas em 42 pacientes portadores de síndrome de imunodeficiência adquirida (AIDS). Rev Bras de Coloproctologia, 17 (2), 105-116, 1997. 
10. Cruz GMG, Silva IG, Teixeira RG, Andrade Filho JS, Pena GPM. Melanoma retal: apresentação de três casos e revisão da literatura. Rev Bras de Coloproctologia, 18 (3), 202-207, 1998.

11. Cruz GMG. Tumores Malignos do Ânus e Canal Anal. In: Castro LP, Rocha PRS, Carvalho DGT. Tópicos em Gastroenterologia 3. Ed. MEDSI, Rio de Janeiro, 1992.

12. Cruz GMG. Papilites e Cripitites Anais. In: Cruz GMG. Livro Livro Texto "Coloproctologia", Volume II "Coloproctologia - Propedêutica Nosológica", Editora Revinter, Rio de Janeiro, RJ, 1999. Vol II, parte VII, cap. 80, 1183 - 1186.

13. Cruz GMG. Tumores malignsos do Ânus e Canal Anal. In: Cruz GMG. Livro Livro Texto "Coloproctologia”, Volume II - "Coloproctologia - Propedêutica Nosológica", Editora Revinter, Rio de Janeiro, RJ, 1999. Vol II, parte VII, cap. 81, 1187 - 1200.

14. Cunha AS. Parasitoses Intestinais. In: Dani R \& Paula Castro L, Gastroenterologia Clínica. Ed. Guanabara $3^{a}$ edição, Ed. Guanabara, Rio de Janeiro, 1995.

15. Fillmann EEP, Fillmann LS. Fístulas Anorretoperineais. In: Cruz GMG. Livro Livro Texto "Coloproctologia", Volume II - "Coloproctologia - Propedêutica Nosológica", Editora Revinter, Rio de Janeiro, RJ, 1999. Vol II, parte VII, cap. 78, 1171 - 1176.

16. Fry, G.A. Martin, W.J., Dearing, W.H. Culp, C.E. Primary actinomycosis of the rectum with multiple perianal and perineal fistulae. Mayo Clinic Proc., 40: 296-259, 1985.

17. Habr-Gama A \& Bocchini SF. Criptites e Papilites. In: Pinotti HW. Tratado de Clínica Cirúrgica do Aparelho Digestivo. ATHENEU, São Paulo, 1994; cap.133:1102-03.

18. Haddad J \& Bocchini SF. Processos Inflamatórios do Canal Anal. In: Corrêa Neto A. Clínica Cirúrgica Alípio Corrêa Neto.SARVIER, São Paulo, 1994; cap.65:640-60.

19. Harland A.W .\& Varkley, B. Anal tuberculosis: Report of two cases and literature review. Am. J. Gastroenterol., 87: 14881491, 1992.

20. Iglésias, JDF. Aspectos Médicos das Parasitoses Humanas. $1^{\text {a }}$ ed. Rio de Janeiro: Ed. MEDSI, 1996.

21. Iglésias JDF. Exames Laboratoriais das Doenças Infectocontagiosas e Parasitárias Anorretais. In: Cruz GMG. Livro Livro Texto "Coloproctologia", Volume I "Coloproctologia - Propedêutica Geral", Editora Revinter, Rio de Janeiro, RJ, 1998. Vol I, parte III, cap. 23, 258-274.
22. Keighley MRB \& Williams NS. Surgery of the Anus, Rectum and Colon. W.B. Saunders Company Ltd., London, 1993.

23. Moura VTL, Vitória MAA, Souto FJD.Propedêutica das parasitoses intestinais. In: Cruz GMG. Livro Livro Texto "Coloproctologia", Volume II - "Coloproctologia Propedêutica Nosológica", Editora Revinter, Rio de Janeiro, RJ, 1999. Vol II, parte VII, cap. 74, 1128 - 1136.

24. Nahas P, Teixeira MG. Doença de Crohn Perineal. In: Cruz GMG. Livro Livro Texto "Coloproctologia", Volume II "Coloproctologia - Propedêutica Nosológica", Editora Revinter, Rio de Janeiro, RJ, 1999. Vol II, parte VII, cap. 84, 1214 - 1216.

25. Neves DP. Parasitologia humana. $9^{\mathrm{a}}$ ed. Rio de Janeiro: Ed. Atheneu; 1995.

26. Nunes A. Exame anatomo-patológico das afecções do ânus e canal anal. In: Cruz GMG. Livro Texto "Coloproctologia", Volume I - "Coloproctologia - Propedêutica Geral", Editora Revinter, Rio de Janeiro, RJ, 1998. Vol , parte III, cap. 22, 255-257.

27. Nunes W. Doenças do Reto e Ânus. Editora MANOLE, Rio de Janeiro, 1981

28. Robins, S.L. Pathologic Basis of Disease- 5th ed, 783-824, W.B. Saunders, 1994.

29. Rosai, J. Ackerman's Surgical Pathology. $8^{\text {th }}$ Ed. Mosby, Cap. 11. 800-814, 1995 .

30. Santos HA. Doença Hemorroidária. In: Cruz GMG. Livro Livro Texto "Coloproctologia", Volume II - "Coloproctologia - Propedêutica Nosológica”, Editora Revinter, Rio de Janeiro, RJ, 1999. Vol II, parte VIII, cap. 75, 1139 - 1156.

31. Shidham VB. A rapid, economical, and simple method for concentration of Schistosoma mansoni ova in feces. Am J Clin Pathol, 1991; 95:91-5.

32. Singh,R. Nime, R. Mittelman, A. Malignant epithelial tumors of the anal canal. Cancer, 48: 411,1981.

33. Stevens, A. \& Lowe, J. Patologia. 1a. ed. Editora Manole, 513-519, 1996.

34. Wexner SD. Sexually transmitted diseases of the colon, rectum and anus. Dis Colon Retum, 1990;1048-62.

\section{Endereço para correspondência:}

GERALDO MAGELA GOMES DA CRUZ

Rua Rio de Janeiro, 2017 / apartamento 1401, Lourdes

CEP: 30160-042

Belo Horizonte, MG 